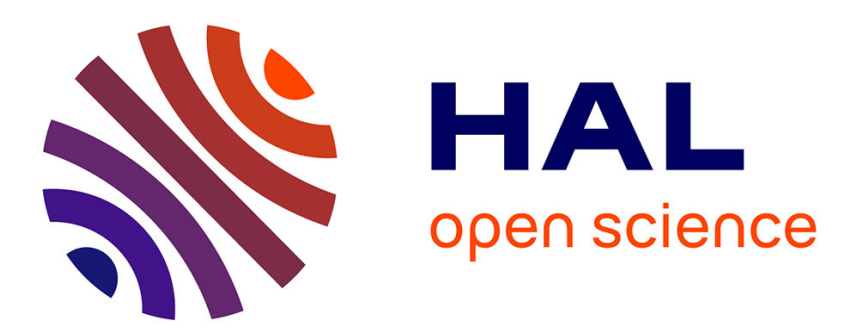

\title{
Stability and Electronic Spectra of the Copper(I1) Chloro Complexes in Aqueous Solutions
}

\author{
M A Khan, M J Schwing-Weill
}

\section{To cite this version:}

M A Khan, M J Schwing-Weill. Stability and Electronic Spectra of the Copper(I1) Chloro Complexes in Aqueous Solutions. Inorganic Chemistry, 1976, 15 (9), pp.2202-2205. 10.1021/ic50163a041 . hal03162151

\section{HAL Id: hal-03162151 \\ https://univ-angers.hal.science/hal-03162151}

Submitted on 10 Mar 2021

HAL is a multi-disciplinary open access archive for the deposit and dissemination of scientific research documents, whether they are published or not. The documents may come from teaching and research institutions in France or abroad, or from public or private research centers.
L'archive ouverte pluridisciplinaire HAL, est destinée au dépôt et à la diffusion de documents scientifiques de niveau recherche, publiés ou non, émanant des établissements d'enseignement et de recherche français ou étrangers, des laboratoires publics ou privés. 
(14) M. Chevreton and A. Sapet. C. R. Hebd. Seances Acad. Sci., 261, 928 (1965); S. Brunie and M. Chevreton, ibid., 258, 5847 (1964).

(15) F. R. Gamble, J Solid State Chem. 9, 358 (1974).

(16) A. Madhukar, Solid State Commun., 16, 383 (1975).

(17) L. Pauling, "The Nature of the Chemical Bond", 3d ed, Cornell University Press, Ithaca, N.Y., 1960, p 98
(18) A. Bondi, J. Phys. Chem., 68, 441 (1964)

(19) R. J. Gillespie, "Molecular Geometry", Van Nostrand-Reinhold, New York, N.Y., 1972, p 158: see also J. Galy, G. Meunier, S. Andersson, and A. Àstrom, J. Solid State Chem., 13, 142 (1975).

(20) W. Lotz, J. Opt. Soc. Am., 60, 206 (1970).

(21) S. Kabashima, J. Phys. Soc. Jpn., 21, 945 (1966)

Contribution from the Laboratoire de Physico-Chimie des Composés de Coordination et des Solutions Electrolytiques, Institut de Chimie de l'Universite Louis Pasteur 1, 67000 Strasbourg, France

\title{
Stability and Electronic Spectra of the Copper(II) Chloro Complexes in Aqueous Solutions
}

\author{
M. A. KHAN and M. J. SCHWING-WEILL*
}

Received January 22, 1976

AIC60056B

The stability constants and the electronic spectra of the chlorocuprates $\mathrm{CuCl}_{j}\left(\mathrm{U}^{-2}\right)$ - (with $j \leq 4$ ) in aqueous solutions of constant $5 \mathrm{M}$ ionic strength have been calculated from spectrophotometric data at 12 wavelengths ranging from 240 to $780 \mathrm{~nm}$. The calculated spectra are compared to those of solid chlorocuprates and solutions in molten salts or organic solvents, in order to get eventual structural information.

\section{Introduction}

Aqueous solutions of copper(II) chloro complexes, which absorb in the uv and in the visible regions $\left(\lambda_{\max } \sim 250\right.$ and $800 \mathrm{~nm}$ ), have mainly been investigated by spectrophotometric methods $;^{1-14}$ potentiometric studies are not feasible in $\mathrm{Cu}(\mathrm{II})-\mathrm{Cl}^{-}$media. ${ }^{15,16}$

The main studies at constant ionic strength by uv spectrophotometry are those of $\mathrm{McConnel}$ and Davidson, ${ }^{8} \mathrm{Kruh},{ }^{9}$ Lister and Rosenblum, ${ }^{1}$ Wendling et al., ${ }^{10}$ and Libus. ${ }^{14}$ The values found for the stability constant $\beta_{1}$ of $\mathrm{CuCl}^{+}$range from 1 to 3.5 , except Kruh's value $\beta_{1}=0.27$ which has been contested by the author himself.

The overall apparent stability constant $\beta_{2}$ of $\mathrm{CuCl}_{2}$ (according to the equation $\mathrm{Cu}^{2+}+2 \mathrm{Cl}^{-} \rightleftharpoons \mathrm{CuCl}_{2}$ ) has only been determined by McConnel and Davidson who found $\beta_{2}=0.30$ \pm 0.20 at ionic strength $\mu=1$. The overall stability constants $\beta_{3}$ and $\beta_{4}$ have not been determined at all, as the studied media were too poor in chloride ions for any appreciable formation of the $\mathrm{CuCl}_{3}$ and $\mathrm{CuCl}_{4}{ }^{2-}$ ions.

One of us (M.J.S.) has recently published the results of the spectrophotometric investigation, at $25^{\circ} \mathrm{C}$, of copper(II) chloro complexes in aqueous solutions of constant ionic strength 5 $\mathrm{M}$ containing $\mathrm{NaClO}_{4}-\mathrm{NaCl}$ mixtures. ${ }^{17}$ This high ionic strength was especially chosen in order to promote formation of the most chlorinated complexes. Eventual formation of polynuclear complexes was avoided by always keeping the copper analytical concentration $\gamma$ lower than the chloride analytical concentration $C$. Copper hydrolysis was prevented by adjusting the $\mathrm{pH}$ of all studied solutions to 2 , with perchloric acid.

The optical densities of 37 different solutions with $C$ ranging from 0.005 to 4.9 and $\gamma$ equal to $6 \times 10^{-4}$ (up to $C=0.2 \mathrm{M}$ ) and $6 \times 10^{-3}$ (for $0.2<C \leq 4.9$ ) were measured at six different wavelengths, i.e., $230,250,280,360,380$, and 756 $\mathrm{nm}$.

The matrix rank treatment of Hugus and El-Awady, ${ }^{18}$ applied to the measured optical densities, showed unambiguously that a minimum of four chloro complexes have to be taken into account in order to interpret the whole set of data.

Under the chosen experimental conditions, only mononuclear complexes $\mathrm{CuCl}_{j}{ }^{(\mathrm{j}-2)-}$ have been considered, e.g., $\mathrm{CuCl}^{+}$, $\mathrm{CuCl}_{2}, \mathrm{CuCl}_{3}^{-}$and $\mathrm{CuCl}_{4}{ }^{2-}$.

The simultaneous least-squares treatment of the 152 data obtained at $250,280,360,380$, and $756 \mathrm{~nm}$ leads to the following values of the $95 \%$ probability ranges of the overall apparent stability constants $\beta_{j}=\left[\mathrm{CuCl}_{j}{ }^{(j-2)-}\right] /\left[\mathrm{Cu}^{2+}\right]\left[\mathrm{Cl}^{-}\right]^{j}$ : $\beta_{1}$ is $3.1-4.9 ; \beta_{2}$ is $3.7-5.7 ; \beta_{3}$ is $1.26-1.94 ; \beta_{4}$ is $0.14-0.17$.
The given ranges correspond to four times the standard deviations. The central values of the constants, $\beta_{1}=4.0, \beta_{2}$ $=4.7, \beta_{3}=1.60$, and $\beta_{4}=0.17$, allowed the recalculation within $1 \%$ of all the measured optical densities.

We report here the results of our extension of the previous study, made in order to determine the electronic spectra of the four chloro complexes in aqueous solutions. We have measured the optical densities at seven more wavelengths, e.g., $240,260,300,340,400,720$, and $780 \mathrm{~nm}$, under the same experimental conditions as in the previous work. ${ }^{17}$ The stability constants have been refined with the complete set of all experimental data, including those of the previous study (324 experimental data in all, excluding those at $230 \mathrm{~nm}$ ), and the specific extinction coefficients of each chloro complex at the various wavelengths have been adjusted.

\section{Method of Calculation}

At the wavelength $\lambda$, the apparent molar extinction coefficient $\epsilon$ of a solution of copper(II) analytical concentration $\gamma$ and chloride analytical concentration $C$ is given by

$$
\epsilon-\epsilon_{0}=\epsilon^{\prime}=\frac{\sum_{j=1}^{n} \epsilon_{j}^{\prime} c^{j} \beta_{j}}{1+\sum_{j=1}^{n} c^{j} \beta_{j}}
$$

where: $\epsilon_{0}$ is the specific extinction coefficient of the $\mathrm{Cu}^{2+}$ ion at wavelength $\lambda ; \epsilon_{j}^{\prime}=\epsilon_{j}-\epsilon_{0} ; \epsilon_{j}$ is the specific extinction coefficient of the $\mathrm{CuCl}_{j}{ }^{(j-2)-}$ ion at wavelength $\lambda ; c$ is the free chloride ion concentration; and $n$ is the number of chloro complexes taken into account $(n=4)$.

The unknowns in eq 1 are the $\beta_{j}, c$, and $\epsilon_{j}^{\prime}$ values ( $\epsilon_{0}$ has been determined experimentally).

The $c$ values for each solution have been calculated by an iterative process, which was stopped either when the difference between the results of two successive iterations was smaller than $10^{-6}$, or when the total number of successive iterations exceeded five. ${ }^{19,20}$

For a given set $\left|\beta_{j}\right\rangle$ of $\beta_{j}$ values, the sum $S^{\lambda}$ of the squares of the relative errors on $\epsilon^{\prime}$ at wavelength $\lambda$ has been optimized by a least-squares treatment leading to the best $\epsilon_{j}^{\prime}$ values for the given $\left|\beta_{j}\right\rangle$ set and to the corresponding $S^{\lambda}\left(\left|\beta_{j}\right\rangle\right)$. The total sum $S(|\beta\rangle)=\sum_{\lambda} S^{\lambda}\left(\left|\beta_{j}\right\rangle\right)$ has then been computed, as well as the standard deviation $\sigma^{\lambda}\left(\left|\beta_{j}\right\rangle\right)$ at wavelength $\lambda$

$\sigma^{\lambda}\left(\left|\beta_{j}\right\rangle\right)=\sqrt{S^{\lambda} /(N-n)}$

$N$ being the number of solutions investigated at wavelength 


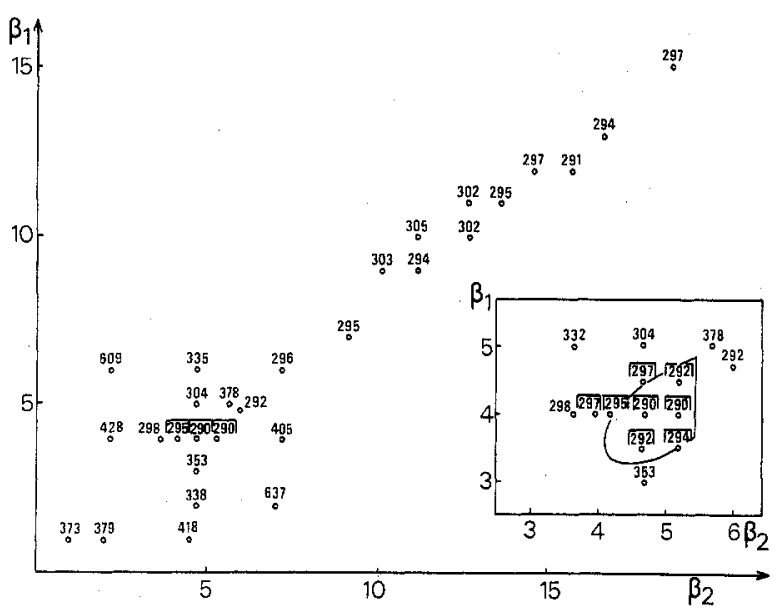

Figure 1. $10^{4} S_{\mathrm{m}}=f\left(\beta_{1}, \beta_{2}\right)$. (The framed values correspond to positive $\epsilon_{j}$ values).

$\lambda$; and the standard deviation $\sigma\left(\left|\beta_{j}\right\rangle\right)$ which defines the precision with which the whole set of $N^{\prime}$ measurements (here $N^{\prime}=324$ ) performed at $L$ different wavelengths (here $L=$ $12)$ is interpreted

$\sigma\left(\left|\beta_{j}\right\rangle\right)=\sqrt{S /\left(N^{\prime}-P\right)}$

with $P=n(L+1)$ (here $P=52$ ).

The calculations have been performed with a UNIVAC 1108 computer by systematic tabulation of $S\left(\left|\beta_{j}\right\rangle\right)$, the $(n L)$ values of $\epsilon_{j}^{\prime}\left(\left|\beta_{j}\right\rangle\right)$, the $L$ values of $S^{\lambda}\left(\left|\beta_{j}\right\rangle\right)$ and $\sigma^{\lambda}\left(\left|\beta_{j}\right\rangle\right)$, as well as $S\left(\left|\beta_{j}\right\rangle\right)$ and $\sigma\left(\left|\beta_{j}\right\rangle\right)$.

For each couple $\left|\beta_{1}, \beta_{2}\right\rangle$, the best values of $\beta_{3}$ and $\beta_{4}$, i.e., those which minimize the sum $S=\sum_{\lambda} S^{\lambda}$, have been determined, as well as the corresponding minimum value $S_{\mathrm{m}}\left(\beta_{1}, \beta_{2}\right)$ of $S$.

\section{Results and Discussion}

Figure 1, which gives the values of $S_{\mathrm{m}}\left(\beta_{1}, \beta_{2}\right)$ vs. $\beta_{1}$ and $\beta_{2}$, provides evidence that $S_{\mathrm{m}}$ remains small $\left(0.0290 \leq S_{\mathrm{m}} \leq\right.$ 0.0300 ) along a "valley"; nevertheless, any point in this valley cannot be suitable because of the necessity for all $\epsilon_{j}$ to be positive. Only the framed values on Figure 1 correspond to a complete set of 48 positive values of the $\epsilon_{j}$ and thus the zone of the possible $\beta_{1}$ and $\beta_{2}$ values, enlarged in the inset of Figure 1 , is considerably restricted. It may be seen also that near its minimum, the surface $S_{\mathrm{m}}\left(\beta_{1}, \beta_{2}\right)$ is not a paraboloid but a hyperboloid.

The dispersion zone for $\beta_{1}$ and $\beta_{2}$ corresponding to $95 \%$ confidence is drawn on the inset of Figure 1. It has been defined by both conditions: (i) $S_{\mathrm{m}}\left(\beta_{1}, \beta_{2}\right) \leq 0.0290+4 \sigma^{2}$ with $\sigma=0.01$; and (ii) all $\epsilon_{j} \geq 0$.

The best values of $\beta_{1}$ and $\beta_{2}$ thus obtained range from 3.3 to 4.7 for $\beta_{1}$ and from 4.1 to 5.3 for $\beta_{2}$. The corresponding best values of $\beta_{3}$ and $\beta_{4}$ have been found ranging from 1.71 to 2.21 for $\beta_{3}$ and 0.18 to 0.28 for $\beta_{4}$. The uncertainties given on $\beta_{3}$ and $\beta_{4}$ are defined by the intersection of the paraboloid approximating $S\left(\beta_{3}, \beta_{4}\right)$ near its minimum with the plane of ordinate $S_{\mathrm{m}}\left(\beta_{3}, \beta_{4}\right)+4 \sigma^{2}$.

The value of $\sigma$, corresponding to the central values $\beta_{1}=4.0$, $\beta_{2}=4.7, \beta_{3}=1.96$, and $\beta_{4}=0.23$, is equal to 0.0103 , which means that the 324 experimental data collected at 12 wavelengths can be recalculated within $1.03 \%$.

The optimized values of the specific extinction coefficients of the four chloro complexes at 13 wavelengths are given in Table I, together with the $S^{\lambda}$ and $\sigma^{\lambda}$. Figure 2 shows the calculated electronic spectra of the four complexes and Figure 3 gives their formation curves.

Figure 2 shows that the first three complexes $\mathrm{CuCl}^{+}, \mathrm{CuCl}_{2}$, and $\mathrm{CuCl}_{3}{ }^{-}$have only one absorption band in the uv region,
Table I. Numerical Interpretation of the Experimental Data with the Refined Values of the Stability Constants: $\beta_{1}=4 ; \beta_{2}=4.7$; $\beta_{3}=1.96 ; \beta_{4}=0.23$

\begin{tabular}{ccccclcc}
\hline$\lambda$ & $\epsilon_{1}$ & $\epsilon_{2}$ & $\epsilon_{3}$ & $\epsilon_{4}$ & \multicolumn{1}{c}{$S^{\lambda}$} & $\sigma^{\lambda}$ & $N$ \\
\hline $230^{a}$ & 655 & 1074 & 1586 & 2146 & 0.01896 & 0.0356 & 19 \\
240 & 867 & 2321 & 1860 & 3272 & 0.0005326 & 0.005 & 25 \\
250 & 1042 & 2424 & 2227 & 2885 & 0.001129 & 0.0065 & 31 \\
260 & 846 & 2349 & 2847 & 3633 & 0.000586 & 0.0053 & 25 \\
280 & 213 & 906 & 2708 & 2578 & 0.002274 & 0.0086 & 35 \\
300 & 13.3 & 440 & 1128 & 1864 & 0.005019 & 0.0155 & 25 \\
340 & 3.03 & 32.6 & 156 & 396 & 0.002533 & 0.0119 & 22 \\
360 & 0.45 & 17.8 & 90.7 & 290 & 0.006632 & 0.0174 & 26 \\
380 & 0.36 & 4.39 & 54.5 & 276 & 0.003238 & 0.0119 & 27 \\
400 & 0.24 & 0.02 & 25.6 & 216 & 0.002044 & 0.0099 & 25 \\
720 & 12.8 & 18.9 & 26.2 & 19.9 & 0.001658 & 0.0083 & 28 \\
756 & 16.3 & 24.2 & 34.4 & 34.8 & 0.001229 & 0.0073 & 27 \\
780 & 17.8 & 27.4 & 38.8 & 37.9 & 0.002177 & 0.0095 & 28 \\
\multicolumn{7}{c}{ Data relative to this wavelength have not been taken into } \\
account for the refinement of the stability constants.
\end{tabular}

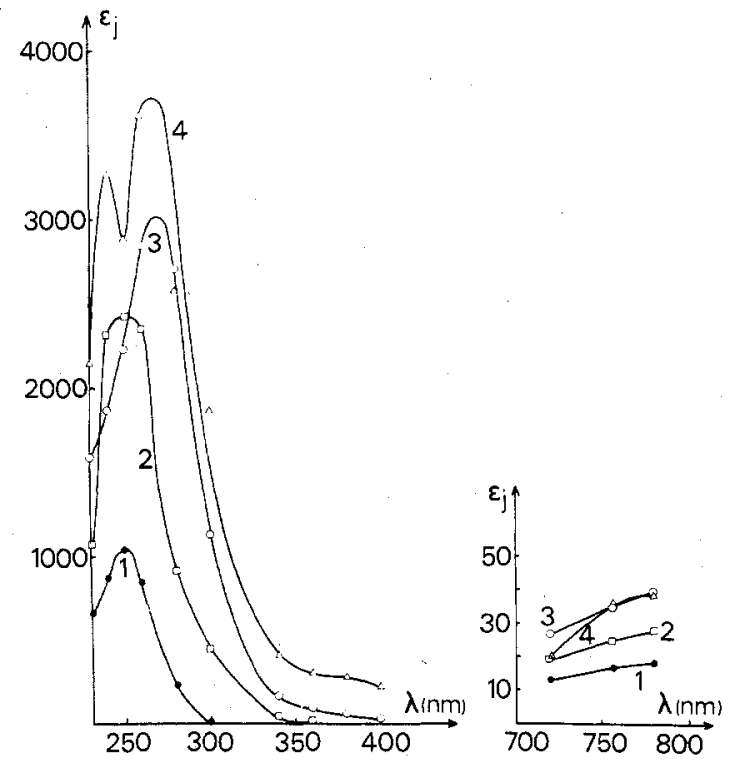

Figure 2. Electronic spectra of the four chloro complexes.

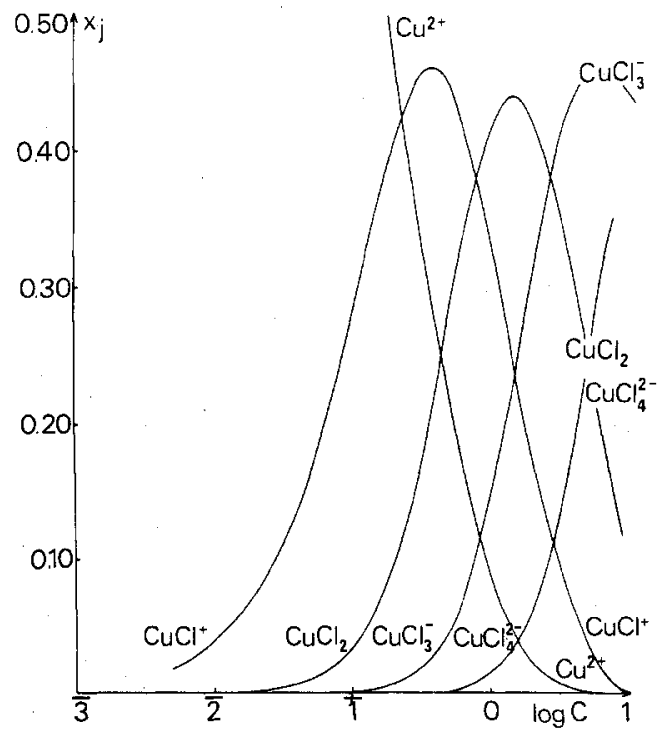

Figure 3. Formation curves of the chloro complexes: $x_{j}=\beta_{j} c^{j} /[1$ $\left.+\Sigma_{j=1}{ }^{4} \beta_{j} c^{j}\right]$.

respectively situated at $250 \mathrm{~nm}\left(40000 \mathrm{~cm}^{-1}\right)$ for $\mathrm{CuCl}^{+}$and $\mathrm{CuCl}_{2}$, and at $270 \mathrm{~nm}\left(37000 \mathrm{~cm}^{-1}\right)$ for $\mathrm{CuCl}_{3}-\mathrm{CuCl}_{4}{ }^{2-}$ has three peaks at $240 \mathrm{~nm}\left(41700 \mathrm{~cm}^{-1}\right), 265-270 \mathrm{~nm}$ 
$\left(37800-37000 \mathrm{~cm}^{-1}\right)$, and $370-380 \mathrm{~nm}\left(27000-26300 \mathrm{~cm}^{-1}\right)$.

It has already been reported in the previous paper ${ }^{17}$ that when the analytical chloride concentration is progressively increased: (i) the absorption peak observed at $250 \mathrm{~nm}$ for $C$ values inferior to $1 \mathrm{M}$ is progressively shifted toward $265 \mathrm{~nm}$; and (ii) a shoulder appears in the spectra around $380 \mathrm{~nm}$ for $C>2.5 \mathrm{M}$. Our present results, summarized on Figures 2 and 3, explain these two observations: (i) the shift of the uv band is due to the successive formation of $\mathrm{CuCl}_{3}{ }^{-}$and $\mathrm{CuCl}_{4}{ }^{2-}$ which maxima are situated at higher wavelengths $(270 \mathrm{~nm})$ than $\mathrm{CuCl}^{+}$and $\mathrm{CuCl}_{2}(250 \mathrm{~nm})$; and (ii) the shoulder at 380 $\mathrm{nm}$ corresponds to the formation of $\mathrm{CuCl}_{4}{ }^{2-}$ which is not appreciable for $C$ values inferior to $2 \mathrm{M}$.

Stability of the Complexes. The central values of $\beta_{1}$ and $\beta_{2}$ calculated in the present work are strictly identical with those determined in our previous work from measurements at five wavelengths, but the confidence interval $\pm 2 \sigma$ is now found smaller. The central values of $\beta_{3}$ and $\beta_{4}$ are slightly different, but the new values are enclosed in the confidence interval given in the previous work.

The value of $\beta_{1}$, ranging from 3.3 to 4.7 , is about four times higher than the values calculated by McConnel and Davidson (1.3 for $\mu=1$ ), Lister and Rosenblum (1.1-1.3 for $\mu=2)$, and Libus (1.63 for $\mu=0$ ) from measurements in the uv region, with low chloride concentrations, and $\lambda>c$ in order to minimize the formation of $\mathrm{CuCl}_{2}$.

Two reasons may account for this difference: (i) As already pointed out by Lister and Rosenblum, the experimental conditions chosen by these authors may be favorable to the formation of polynuclear complexes such as $\mathrm{Cu}_{2} \mathrm{Cl}^{3+}$, the presence of which could explain the abnormal variation of $\beta_{1}$ with temperature observed by Lister and the abnormal variation of $\epsilon_{1}$ with ionic strength reported by Libus. (ii) These authors have based their interpretation on the assumption that $\mathrm{CuCl}^{+}$is the only chloro complex present in solution. Their main argumentation is the linearity of the graph $\gamma / d$ vs. $1 / C$ ( $d=$ optical density). In fact, Schwing has shown that, at 230, 250,280 , and $756 \mathrm{~nm}$, it is possible to interpret the data up to $C=0.5 \mathrm{M}$ with an excellent precision by assuming the presence of $\mathrm{CuCl}^{+}$exclusively, but the values of $\beta_{1}$ thus calculated vary with the wavelength. ${ }^{17}$ The linearity of the graph $\gamma / d$ vs. $1 / C$ is in most cases a sign of the presence of one complex only, but it may happen that such a linearity is observed although more than one complex is present, provided that the $\beta_{j}$ and $\epsilon_{j}$ values satisfy specific conditions. ${ }^{9}$

One may question our not taking into account the variation of the different ions activity factors when $\mathrm{ClO}_{4}{ }^{-}$ions are progressively replaced by $\mathrm{Cl}^{-}$ions. This question has already been raised and discussed in our previous paper, in connection with the recent similar studies of the lead chloro complexes performed in our laboratory. 19,20

Electronic Spectra and Structure of the Copper(II) Chloro Complexes. (1) $\mathrm{CuCl}^{+}, \mathrm{CuCl}_{2}$, and $\mathrm{CuCl}_{3}{ }^{-}$. It is not possible to compare the calculated spectra of mono-, di-, and trichlorocuprates in aqueous solutions to those of analogous solid compounds, as there is no solid chlorocuprate consisting of well-defined units made of one copper atom surrounded by one, two, or three chlorine atoms. In solid $\mathrm{CuCl}_{2}$, each copper atom has a deformed octahedral environment consisting either of six chlorine atoms in the case of anhydrous $\mathrm{CuCl}_{2}{ }^{21}$ or of four chlorine atoms and two oxygen atoms in the case of $\mathrm{CuCl}_{2} \cdot 2 \mathrm{H}_{2} \mathrm{O} .{ }^{22}$ The spectrum of the latter exhibits one single maximum in the uv region at $280 \mathrm{~nm}$.

It has generally been admitted up to now that the monochlorocuprate charge transfer band is centered on 250-255 $\mathrm{nm}$. Our results confirm this assumption.

Wendling ${ }^{10}$ has assigned this band to the less energetic charge transfer transition $t_{2 u} \rightarrow e_{g}$ of a pseudo-octahedral ion
$\left[\mathrm{Cu}\left(\mathrm{H}_{2} \mathrm{O}\right)_{5} \mathrm{Cl}\right]^{+}$, and has calculated the corresponding absorption wavelength $\lambda 256 \mathrm{~nm}$, which is in excellent agreement with our experimental value.

It is probable that for $\mathrm{CuCl}_{2}$ in aqueous solutions the copper environment is pseudooctahedral too, four water molecules being coordinated to each copper atom, the two chlorine atoms occupying both axial positions in order to minimize their mutual electrostatic repulsion.

(2) $\mathrm{CuCl}_{4}{ }^{2-}$. The molecular structure of $\mathrm{CuCl}_{4}{ }^{2-}$ has been extensively studied, as well in the solid state ${ }^{23-32}$ as in molten salts solutions s $^{33,34}$ or in organic solvents such as acetonitrile or nitromethane. ${ }^{35-37}$

Its structure in the solid state depends on the nature of the cation which is associated with the $\mathrm{CuCl}_{4}{ }^{2-}$ anion: $\mathrm{x}$-ray structural studies have shown that in $\mathrm{Cs}_{2} \mathrm{CuCl}_{4}{ }^{23,32}$ and $\left[\mathrm{N}\left(\mathrm{CH}_{3}\right)_{4}\right]_{2} \mathrm{CuCl}_{4},{ }^{32}$ the copper atom is at the center of a flattened tetrahedron $\left(D_{2 d}\right.$ symmetry) while in $\left(\mathrm{NH}_{4}\right)_{2} \mathrm{Cu}$ $\mathrm{Cl}_{4},{ }^{30}\left[\mathrm{Pt}\left(\mathrm{NH}_{3}\right)_{4}\right] \mathrm{CuCl}_{4},{ }^{24}\left(\mathrm{C}_{2} \mathrm{H}_{5} \mathrm{NH}_{3}\right)_{2} \mathrm{CuCl}_{4},{ }^{30,31}$ and $\left(\mathrm{CH}_{3} \mathrm{NH}_{3}\right)_{2} \mathrm{CuCl}_{4},{ }^{31}$ the chlorine atoms form a tetragonally distorted octahedral environment around each copper atom, with two axial bonds so long ( $2.8 \AA)$ that it is commonly admitted that in fact the copper atoms are in a square-planar environment ( $D_{4 h}$ symmetry).

The previous works show two main differences between the spectra of the $D_{2 d}$ and $D_{4 h}$ configurations: (i) the presence of a band between 435 and $455 \mathrm{~nm}$ for the $D_{2 d}$ form:25 and (ii) the absence of any $\mathrm{d}-\mathrm{d}$ transition band below $1100 \mathrm{~nm}$ for the $D_{2 d}$ configuration, whereas the configuration $D_{4 h}$ presents two bands at lower wavelengths, between 700 and 800 $\mathrm{nm}$, and between 900 and $950 \mathrm{~nm}$. The structure of $\mathrm{CuCl}_{4}{ }^{2-}$ in aqueous solution is a controversial problem. On the basis of the similarity between the spectra of solid $\mathrm{Cs}_{2} \mathrm{CuCl}_{4}$ and a $\mathrm{Cs}_{2} \mathrm{CuCl}_{4}$ aqueous solution (in the presence of a large excess of chloride), Helmholz and Kruth conclude in favor of an identity of structures, although the positions of the bands as well as their relative intensities are slightly different. ${ }^{23}$ On the other hand, for Eswein and co-workers, $\mathrm{CuCl}_{4}{ }^{2-}$ in aqueous solution would rather have a square-planar structure because the characteristic absorption band at $450 \mathrm{~nm}$ of the $D_{2 d}$ configuration has never been observed in highly donor solvents such as water, alcohols, or molten chlorides; ${ }^{38}$ this band is visible in a mixed acetic anhydride-acetic acid solvent, but disappears by addition of chloride or water. Eswein therefore suggests that there is an equilibrium in solution between the $D_{2 d}$ and $D_{4 h}$ configurations which can be strongly displaced by medium effects such as water or chloride concentrations. We think that this statement is plausible because of the small energy difference between both configurations: recent $a b$ initio LCAO-MO-SCF calculations show that the $T_{d}$ configuration is about $18 \mathrm{kcal} / \mathrm{mol}$ more stable than the $D_{4 h}$ one, and that the intermediate $D_{2 d}$ configuration is about $2 \mathrm{kcal} / \mathrm{mol}$ more stable than the $T_{d}$ one. ${ }^{39}$ Thus the calculated energy differences between $D_{4 h}$ and $D_{2 d}$ configurations are sufficiently small to account for an appreciable influence of the surrounding medium upon the geometry of the $\mathrm{CuCl}_{4}{ }^{2-}$ anion.

Our calculated spectrum of $\mathrm{CuCl}_{4}{ }^{2-}$ is consistent with the spectra generally admitted for $\mathrm{CuCl}_{4}{ }^{2-}$ in aqueous solutions. ${ }^{23,42-44}$

It would be very hazardous to draw any structural conclusion from the positions of these bands, especially as the differences between the $D_{2 d}$ and the $D_{2 h}$ configurations are most obvious in the $d-d$ transition region which we unfortunately could not explore beyond $800 \mathrm{~nm}$ because of the lack of an appropriate spectrophotometer. The absence of any band at $450 \mathrm{~nm}$ as well as the shape of the spectrum between 700 and $800 \mathrm{~nm}$ could be considered as arguments in favor of a square-planar structure, but could by no means be taken as a proof. Moreover, it is not out of question that $\mathrm{CuCl}_{4}{ }^{2-}$ in 
aqueous solutions may have the geometry of a tetragonally distorted octahedron, with two water molecules coordinated to copper. Similar structures have been found in the solid state for $\mathrm{CuCl}_{2} \cdot 2 \mathrm{H}_{2} \mathrm{O}$ made of $\left[\mathrm{CuCl}_{4}\left(\mathrm{H}_{2} \mathrm{O}\right)_{2}\right]^{2-}$ units $^{22}\left(\lambda_{\max } 280\right.$ $\left.\mathrm{nm}^{40}\right)$ and for $\mathrm{LiCuCl}_{3} \cdot 2 \mathrm{H}_{2} \mathrm{O}$ made of $\left[\mathrm{CuCl}_{5}\left(\mathrm{H}_{2} \mathrm{O}\right)\right]^{3-}$ units $\left(\lambda_{\max } 270,380,485 \mathrm{~nm}^{40}\right)$.

Registry No. $\mathrm{CuCl}^{+}, 15697-17-3 ; \mathrm{CuCl}_{2}, 7447-39-4 ; \mathrm{CuCl}_{3}$, 15697-18-4; $\mathrm{CuCl}_{4}^{2-}$, 15489-36-8.

\section{References and Notes}

(1) M. W. Lister and P. Rosenblum, Can. J. Chem., 38, 1827 (1960).

(2) P. Job, C. R. Hebd. Seances Acad. Sci., 198, 827 (1934).

(3) J. Bjerrum, Dan. Kemi, 26, 24 (1945).

(4) J. Bjerrum, $K$. Dan. Vidensk. Selsk., Mat.-Fys. Medd., 22, 1 (1946).

(5) R. Nasanen, Acta Chem. Scand., 3, 179 (1949).

(6) R. Näsanen, Acta Chem. Scand., 4, 140 (1950).

(7) R. Nasanen, Suom. Kemistil. B, 26, 37 (1953).

(8) H. McConnel and N. Davidson, J, Am. Chem. Soc., 72, 3164 (1950).

(9) R. Kruh, J. Am. Chem. Soc., 76, 4865 (1954).

(10) E. Wendling, O. Benali-Baitich, and G. Yaker, Rev. Chim. Miner, , 8, 559 (1971).

(11) V. E. Mironov, Yu. A. Makashev, i. Ya., Marrina, and D. M. Markhaeva, Russ. J. Phys. Chem. (Engl. Transl.), 1592 (1968).

(12) Yu. A. Makashev, F. Ya. Kul'ba, M. I. Agaf, Yu. A. Volokhov, and V. E. Mironov, Russ. J. Phys. Chem. (Engl. Transl.), 414 (1971).

(13) A. E. Klygin, V. A. Glebov, V. A. Lekae, N. S. Kolyada, I. D. Smirnova and N. a. Nikol'skaya, Russ. J. Inorg. Chem. (Engl. Transl.) 840 (1971).

(14) Z. Libus, Inorg. Chem., 12, 2972 (1973).

(15) H. L. Riley and H. C. Smith, J. Chem. Soc., 1448 (1934).

(16) C. W. Davies, J. Chem. Soc., 448 (1938)

(17) M. J. Schwing-Weill, Bull. Soc. Chim. Fr., 3, 823 (1973).

(18) Z. Z. Hugus and A. A. El-Awady, J. Phys. Chem., 75, 2954 (1971).
(19) F. Vierling, Thèse, Strasbourg, 1972.

(20) F. Vierling, Ann. Chim. (Paris), 8, 53 (1973).

(21) A. F. Wells, J. Chem. Soc., 1670 (1947).

(22) D. Harker, Z. Kristallogr., Kristallgeom., Kristallphys., Kristallchem., 93, 136 (1936).

(23) L. Helmholz and R. F. Kruth, J. Am. Chem Soc, 74, 1176 (1952).

(24) M. Bukorska and M. A. Porai-Koshits, Kristallografiya, 5, 127 (1960).

(25) J. Fergusson, J. Chem. Phys., 40, 3406 (1964).

(26) B. Morosin and L. Lawson, J. Mol. Spectrosc., 12, 98 (1964)

(27) D. Mori, Bull. Chem. Soc. Jpn., 34, 1249, 454 (1961).

(28) S. Yamada and R. Tsuchida, Bull. Chem. Soc. Jpn., 27, 436 (1954).

(29) W. E. Hatfield and T. S. Piper, Inorg. Chem., 3, 841 (1964).

(30) R. D. Willett, J. Chem. Phys., 41, 2243 (1964).

(31) R. D. Willett, O. L. Liles, Jr., and C. Michelson, Inorg. Chem., 6, 1885 , (1967).

(32) B. Morosin and E. C. Lingafelter, J. Phys. Chem., 65, 50 (1961).

(33) G. Harrington and B. R. Sundheim, Ann. N. Y. Acad. Sci., 79, 950 (1960).

(34) G. P. Smith and T. R. Griffiths, J. Am. Chem. Soc., 85, 4051 (1963).

(35) S. E. Manahan and R. T. Iwamoto, Inorg. Chem., 4, 1409 (1965).

(36) L. Sestili, C. Furlani, A. Ciani, and F. Garbassi, Electrochim. Acta, 15, $225(1970)$.

(37) C. Furlani and G. Morpurgo, Theor. Chim. Acta, 1, 102 (1963).

(38) R. P. Eswein, E. S. Howald, R. A. Howald, and D. P. Keeton, J. Inorg. Nucl. Chem., 29, 437 (1967).

(39) J. Demuynck, A. Veillard, and U. Wahlgren, J. Am. Chem. Soc., 95, 5563 (1973)

(40) S. N. Andreev and O. V. Sapashnikova, Russ. J. Inorg. Chem. (Engl. Transl.), 1379 (1965).

(41) P. H. Vossos, L. D. Jennings, and R. E. Rundle, J. Chem. Phys., 32, $1590(1960)$

(42) E. Doehlemann and H. Fromherz, Z. Phys. Chem., Abt. A, 171, 371 (1935).

(43) C. K. Jörgensen, "Absorption Spectra and Chemical Bonding in Complexes", Pergamon Press, Oxford, 1962.

(44) L. I. Katzin, J. Chem. Phys., 36, 3034 (1962).

Contribution from the Department of Chemistry,

Purdue University, West Lafayette, Indiana

\title{
Studies on Metal Carboxylates. 12.1 Reactions of Molybdenum(II), Rhodium(II), and Rhenium(III) Acetates with Gaseous Hydrogen Chloride and Hydrogen Bromide
}

\author{
H. D. GLICKSMAN, A. D. HAMER, T. J. SMITH, and R. A. WALTON*
}

Received April 5, 1976

AIC60250Y

Molybdenum(II) acetate $\left(\mathrm{Mo}_{2}\left(\mathrm{O}_{2} \mathrm{CCH}_{3}\right)_{4}\right)$ reacts with gaseous hydrogen chloride and hydrogen bromide at $300^{\circ} \mathrm{C}$ to afford the phases $\beta-\mathrm{MoX}_{2}$, where $\mathrm{X}=\mathrm{Cl}$ or $\mathrm{Br}$. Reaction of these halides with pyridine and monodentate tertiary phosphines to produce metal-metal bonded dimers of the type $\mathrm{Mo}_{2} \mathrm{X}_{4} \mathrm{~L}_{4}$ suggests that they are best formulated as $\left[\mathrm{Mo}_{2} \mathrm{X}_{4}\right]_{n}$ and are accordingly the parent halides of haloanions $\mathrm{Mo}_{2} \mathrm{X}_{8}{ }^{4-}$. In contrast to this behavior, the rhenium(III) acetates, $\mathrm{Re}_{2}-$ $\left(\mathrm{O}_{2} \mathrm{CCH}_{3}\right)_{4} \mathrm{X}_{2}$, where $\mathrm{X}=\mathrm{Cl}$ or $\mathrm{Br}$, react with $\mathrm{HCl}$ and $\mathrm{HBr}$ to yield the trinuclear halides $\mathrm{Re}_{3} \mathrm{X}_{9}$. This is the first instance where a dinuclear rhenium halide containing a quadruple metal-metal bond has been converted to a trinuclear cluster. The related reaction of dinuclear rhodium(II) acetate with $\mathrm{HCl}$ and $\mathrm{HBr}$ differs from those involving $\mathrm{Mo}_{2}\left(\mathrm{O}_{2} \mathrm{CCH}_{3}\right)_{4}$ and $\operatorname{Re}_{2}\left(\mathrm{O}_{2} \mathrm{CCH}_{3}\right)_{4} \mathrm{X}_{2}$ in that disproportionation to $\mathrm{RhX}$ and rhodium metal occurs.

During a study of the $x$-ray photoelectron spectra of transition metal chloride clusters, ${ }^{2}$ we showed that the $\beta$ form of molybdenum(II) chloride ${ }^{3-5}$ is not structurally related to the $\alpha$ form, in which a hexanuclear cluster of molybdenum atoms is known to be present, ${ }^{6}$ and which may, using Schäfer's notation, ${ }^{6}$ be written as $\left[\mathrm{Mo}_{6} \mathrm{Cl}_{8}\right] \mathrm{Cl}_{4 / 2} \mathrm{Cl}_{2}$. In view of the absence of any detailed information concerning the structure of $\beta-\mathrm{MoCl}_{2}$ and the paucity of studies dealing with its chemical reactivity, we decided to explore its chemistry in more detail. In particular, since this phase is prepared by the reaction of molybdenum(II) acetate with hydrogen chloride, we were interested in establishing whether metal-metal bonded $\mathrm{Mo}_{2}$ units, as present in $\mathrm{Mo}_{2}\left(\mathrm{O}_{2} \mathrm{CCH}_{3}\right)_{4}{ }^{7}$ are preserved in this phase. During the course of this work we extended the preparative procedure which has been used ${ }^{3,4}$ to prepare $\beta-\mathrm{MoCl}_{2}$ to include the reactions of $\mathrm{Mo}_{2}\left(\mathrm{O}_{2} \mathrm{CCH}_{3}\right)_{4}$, $\mathrm{Rh}_{2}\left(\mathrm{O}_{2} \mathrm{CCH}_{3}\right)_{4}$, and $\mathrm{Re}_{2}\left(\mathrm{O}_{2} \mathrm{CCH}_{3}\right)_{4} \mathrm{Cl}_{2}$ with both hydrogen chloride and hydrogen bromide. The results of these studies are now reported in detail. ${ }^{8}$

\section{Experimental Section}

Starting Materials. Molybdenum hexacarbonyl, hydrated rhodium(III) chloride, potassium perrhenate, tertiary phosphines and pyridine, together with all reagent-grade solvents and gases, were obtained from commercial sources. All solvents were deoxygenated by purging with nitrogen gas for at least $1 \mathrm{~h}$ prior to use.

The following compounds were prepared by standard literature procedures: $\mathrm{Mo}_{2}\left(\mathrm{O}_{2} \mathrm{CCH}_{3}\right)_{4},{ }^{3} \mathrm{~K}_{4} \mathrm{Mo}_{2} \mathrm{Cl}_{8},{ }^{9} \mathrm{Cs}_{3} \mathrm{Mo}_{2} \mathrm{Br}_{8} \mathrm{H},{ }^{10,11} \mathrm{Rh}_{2}$ - 